East African Medical Journal Vol. 79 No. 12 December 2002

PNEUMATOSIS CYSTOIDES INTESTINALIS ASSOCIATED WITH ASCITES AND PYLORIC STENOSIS SECONDARY TO A CHRONIC DUODENAL ULCER: CASE REPORT

V.M. Muyembe, MBChB, MMed(Surg), Consultant Surgeon, Nyeri Provincial General Hospital, P.O. Box 12485, Nyeri, Kenya

\title{
PNEUMATOSIS CYSTOIDES INTESTINALIS ASSOCIATED WITH ASCITES AND PYLORIC STENOSIS SECONDARY TO A CHRONIC DUODENAL ULCER: CASE REPORT
}

\author{
V.M. MUYEMBE
}

\section{SUMMARY}

\begin{abstract}
A thirty eight year old female with a long standing history of a chronic duodenal ulcer presented at the Nyeri Provincial General Hospital with vomiting, abdominal pain and abdominal distension. Oesophago-gastro-duodenoscopy revealed a tight pyloric stenosis while abdominal ultrasonography showed ascites. At laparatomy, she was coincidentally found to have pneumatosis cystoides intestinalis(PCI). The recent literature is reviewed and this case of PCI associated with ascites and pyloric stenosis secondary to a chronic duodenal ulcer is reported.
\end{abstract}

\section{INTRODUCTION}

Pneumatosis cystoides intestinalis (PCI) is a rare condition characterised by multiple gas filled cysts in the sub-serosa or sub-mucosa of the wall of the small or large bowel. Although it is associated with several conditions, its pathophysiology is yet to be clearly defined. When it occurs, it is associated with intestinal and pulmonary obstructive diseases, recent abdominal procedures, peptic ulcer disease and systemic illnesses. It may also have no known cause(1). Its clinical presentation is non-specific and the diagnosis is often coincidental. The management varies but it is mainly directed at the presumed causative agent or the associated condition. It is benign in nature although it may have serious complications.

\section{CASE REPORT}

A.W.M. was a thirty eight year old female who had been on treatment for a chronic duodenal ulcer since 1984 . She was admitted to the medical ward on 16/11/01 with complaints of vomiting and abdominal distension. On examination, she was found to be sick looking with abdominal distension. Clinically, she had ascites which was confirmed on ultrasonography that showed normal abdominal organs except the stomach, which was dilated and had debris.

Oesophago-gastro-duodenoscopy had been done twice before admission and on both occasions a duodenal ulcer had been visualized. During admission, she underwent a third oesophago-gastroduodenoscopy at which a grossly dilated stomach with a lot of residual gastric fluid was found. The endoscopist reported encountering an extremely tight pyloric sphincter due to a chronic duodenal ulcer. She was referred to the department of surgery where she was admitted.

On admission she wis found to be wasted and had moderate dehydration. She had marked abdominal distension. Several investigations were done including an ascitic tap, which revealed a sugar level of $10.7 \mathrm{mmol} / 1$ and a protein level of $5 \mathrm{gm} / \mathrm{dl}$. Her haemoglobin level was $13.8 \mathrm{~g} / \mathrm{dl}$ with an ESR of $500 \mathrm{~mm} / \mathrm{hr}$. The white cell count was $9.1 \times 109 /$ 1 with a differential count of $76 \%$ neutrophils and $24 \%$ lymphocytes, Elisa test for HIV was negative.

The patient was rehydrated and on 11/01/2002, she was taken to theatre where under general anaesthesia, the abdomen was opened through an upper midline incision. Ascites with about three litres of straw-coloured fluid and a markedly dilated stomach were found.

There was remarkable scarring and tightness of the pylorus. The whole length of the small intestine had multiple sub-serosal cysts varying in size from a pinhead to about $3.5 \mathrm{~cm}$ by $3.5 \mathrm{~cm}$. The large intestine was normal as were the rest of the abdominal organs. The ascitic fluid was aspirated. Truncal vagotomy and pyloroplasty was done. A Ryle's tube was left in place for five days. After its removal, the patient was started on graduated feeding with no abdominal pain, distension or vomiting reported. The wound healed in the normal expected time. She was discharged in good condition ten days after surgery. She was seen four weeks after discharge when she was found to be in good general condition with absence of all the previous symptoms. After this visit, she has not been seen again.

\section{DISCUSSION}

PCI has non-specific features of presentation but abdominal distension and pain seem to be the commonest symptoms(2-7). These are however found in many other conditions and since PCI is rare, its diagnosis based on the above symptoms can be difficult. Hence most cases are diagnosed incidentally. Other presenting features of PCI are diarrhoea, loss of appetite, weight loss $(1,2,4,7)$, rectal mass and bloody stools $(8)$.

The aetiology of PCI remains unclear to date. Several conditions have been associated with it but the pathophysiology is yet to be conclusively worked out. Strictly, PCI is not a disease in its own right but a complication of very different, in part, extra-intestinal diseases. Some of the diseases associated with PCI are polymyositis(3), myotonic dystrophy(9), mixed connective 
tissue disease(6), progressive systemic sclerosis(10,11), systemic lupus erythematosus with intestinal vasculitis(7) and chronic duodenal ulcer with pyloric stenosis(12). PCI has also been reported following treatment for haematological disorders $(13,14)$, recent abdominal procedures(1) and obstructive pulmonary diseases(7).

Theegarten and Ruhl(15) conveniently divide patients with PCI into three groups. These are: Group 1-Patients with PCI as a complication of lung disease and initially normal intestinal status.

Group 2-Patients who develop pneumatosis on the grounds of intestinal disease secondary to primary extraintestinal or generalised disease.

Group 3-Patients who develop PCI as a complication of primary gastro-intestinal disease.

After thorough search of literature, the author was unable to find a reported case of PCI associated with ascites as in the present one.

Both simple and advanced investigations have been useful in situations where PCI is suspected. A plain abdominal radiograph usually shows gas cysts in the wall of the affected bowel. A barium enema is useful in the demonstration of gas cysts where the large bowel is affected. Colonoscopy has been used to visualise gas cysts in the submucosa of the colon $(1-3,7,8,11,13,14)$. Gas cysts in the wall of the intestine, especially in the intramural part, can be seen on CT $\operatorname{scan}(9,16)$ Ultrasonography is also invaluable and it can be used to show the presence of multiple cysts in the bowel wall. Wakamatsu et al (6) observed atrophy and fibrosis of the inner circular muscle layer of the small bowel in a patient with $\mathrm{PCI}$ and progressive systemic sclerosis.

Several modalities of treatment for PCI have been tried. Broad spectrum antibiotics, metronidazole, steroids (predisone), high flow oxygen and hormones (somatostatin analogue) have been tried with good results $(2,3,7,9,11)$. Bismuth has also been used but it requires long term administration and this can lead to generalised skin pigmentation and bismuth poisoning(17). Surgery is useful only in situations where PCI is complicated by acute abdomen or when the underlying cause of the PCI is amenable to surgical treatment as in obstructive gastro-intestinal disease or perforation leading to peritonitis $(5,8,18)$. Measures aimed at treating or correcting the underlying cause of the PCI must always be instituted(19).

The death observed in a reported case of PCI seems to be attributable to the underlying cause of the PCI rather than to the PCI per se.(6).

\section{ACKNOWLEDGEMENTS}

To the administration of the Provincial General Hospital, Nyeri, for allowing me to reporting this case and Lords Healthcare for literature search.

\section{REFERENCES}

1. Sabiston, D.C. Davis-Christopher Textbook of surgery, $15^{\text {th }}$ Edition, W.B. Saunders Co. Philadelphia, 1997

2. Ibara, B.I. Bossali, F. Ossendza, R.A., et al. A. Pneumatosis cystoides intestinalis: the first case in Congo. Sante. 2001; 11: 131-132.

3. Kuroda, T., Ohfuchi, Y., Hirose, S., et al. Pneumatosis cystoides intestinalis in a patient with polymyositis. Clinical rheumatology. 2001; 20:49-52.

4. Azami, Y. Paralytic ileus accompanied by pneumatosis cystoides intestinalis after acarbose treatment in an elderly diabetic patient with a history of heavy intake of maltitol. Internal medicine. 2000; 39:826-829.

5. D’Agostino, S., Fabbro, M.A., Musi, L. and Bozzola, L. Pneumatosis cystoides intestinalis: a rare cause of non-surgical Pneumoperitoneum in an infant. $J$. pediat. surg. 2000; 135: 1106-1108.

6. Wakamatsu, M., Inada, K. and Tsutsumi, Y. Mixed connective tissue disease complicated by pneumatosis cystoides intestinalis and malabsorption syndrome. Pathology international. 1995; 45:875-878

7. Cabrera, G.E., Scopelitis, E., Cuellar, M.L., et al. Pneumatosis cystoides intestinalis in systemic lupus erythematosus with intestinal vasculitis. Clinical rheumatology. 1994; 13:312-316.

8. Quintart, C., Choghari, C., Michez, D., Lefebvre. P. and Ramdani, B. Pneumatosis cystoides intestinalis: Diagnostic elements and therapeutic approach. Annales de clururgie. 1997; 51:1032-1035.

9. Boland, C., De Ronde, T., Lacrosse, M., Trigaux, J.P., Delaunois, $L$. and Melange, M. Pneumatosis cystoides intestinalis associated with Steinert disease. Gastroenterologie clinique el biologique. 1995; 19:305-308

10. Quiroz, E.S., Flannery, M.T., Martinez, E.J. and Warner, E.A Pncumatosis cystoides intestinalis in progressive systemic sclerosis. Amer. J. Med. Sci. 1995; 310:252-255.

11. Kobayashi, T., Kobayashi, M., Naka, M., Nakajima, K. Momose, A. and Toi, M. Response to octreotide of intestinal pseudo-obstruction and pneumatosis cystoides intestinalis associated with progressive systemic sclerosis. Internal medicine. 1993; 32:607-609.

12. Gangemi, V., Galati, G., Volpino, P., Mingazzini, P., Martinazzoli, A., Piat G. Pneumatosis cystoides intestinalis: Etiopathogenic and clinical considerations regarding a case. Minerve chirurgica. 1993; 48:637-641.

13. Gabel, A., Muller, S., liantzsche, K.and Dauwel, N. Pneumatosis cystoides intestinalis:an unexpected finding in intestinal bleeding under therapy with phenprocoumon. Digestion. 2000; 61:215218 .

14. Hashimoto, S., Saitoh, H., Wada, K., et al. Pneumatosis cystoides intestinalis after chemotherapy for hematological malignancies. Internal medicine. 1995; 34:212-215.

15. Theegarten, D. and Ruhl, G.H. Pneumatosis cystoides intestinalis: associated diseases, morphology and presumed pathogenesis. Leber. Megen. Darm. 1994; 24:123-124:127-130.

16. Hosoni, N., Yoshioka, H., Kuroda, C., et al. II. Pneumatosis cystoides intestinalis: CT findings. Abdominal imaging. 1994; 19:137-139.

17. Zala, L., Hunziker, T. and Braathen, L.R. Pigmentation following long-term bismuth therapy for pneumatosis cystoides intestinalis. Dermatology. 1993; 187:288-289.

18. Kaassis, M., Ben Bouali, A. and Arnaud, J.P. Occlusive pneumatosis cystoides intestinalis of the left colon. $J$. de chirurgie. 1995; 132:183-185

19. Aziz, M.R., Wandwi, W.B. and Mkony, C.A. Pneumatosis cystoides intestinalis. Central Afri. J. med. 1995; 41:230-233. 